Acta Crystallographica Section E

Structure Reports

Online

ISSN 1600-5368

S. M. Malathy Sony, ${ }^{a}$ P. Charles, ${ }^{a}$ M. N. Ponnuswamy ${ }^{a *}$ and H. S. Yathirajan $^{b}$

${ }^{\mathrm{a}}$ Department of Crystallography and Biophysics, University of Madras, Guindy Campus, Chennai 600 025, India, and ${ }^{\mathbf{b}}$ Department of Studies in Chemistry, University of Mysore, Manasagangotri, Mysore 570 006, India

Correspondence e-mail:

mnpsy2004@yahoo.com

\section{Key indicators}

Single-crystal X-ray study

$T=293 \mathrm{~K}$

Mean $\sigma(\mathrm{C}-\mathrm{C})=0.005 \AA$

$R$ factor $=0.055$

$w R$ factor $=0.179$

Data-to-parameter ratio $=20.6$

For details of how these key indicators were automatically derived from the article, see http://journals.iucr.org/e.
(C) 2005 International Union of Crystallography Printed in Great Britain - all rights reserved

\title{
Valdecoxib, a non-steroidal anti-inflammatory drug
}

Valdecoxib [systematic name: 4-(5-methyl-3-phenylisoxazol-4yl)benzenesulfonamide], $\mathrm{C}_{16} \mathrm{H}_{14} \mathrm{~N}_{2} \mathrm{O}_{3} \mathrm{~S}$, a diaryl-substituted isoxazole, is a non-steroidal anti-inflammatory drug (NSAID) that is used for the treatment of rheumatoid arthritis, osteoarthritis and dysmenorrhea pain. The planar isoxazole ring is oriented at angles of $22.2(1)$ and $54.3(1)^{\circ}$ with respect to the phenyl and benzenesulfonamide groups, respectively. $\mathrm{N}-\mathrm{H} \cdots \mathrm{O}$ and $\mathrm{C}-\mathrm{H} \cdots \mathrm{O}$ hydrogen bonds and $\mathrm{N}-\mathrm{H} \cdots \pi$, $\mathrm{C}-\mathrm{H} \cdots \pi$ and $\pi-\pi$ interactions stabilize the crystal packing.

\section{Comment}

Valdecoxib, whose brand name is Bextra, is a nonsteroidal anti-inflammatory drug (NSAID) that is used for the treatment of osteoarthritis or rheumatoid arthritis and for the treatment of primary dysmenorrhea (Scheen \& Malaise, 2004). Valdecoxib is a potent and specific inhibitor of cyclooxygenase-2 (COX-2), an isoform of cyclo-oxygenase which is the key enzyme catalysing the inversion of arachidonic acid into prostaglandins and thromboxane (Coats et al., 2004). COX-2 is an inducible enzyme that is primarily found in inflammatory cells and tissues and so the inhibition of this enzyme by valdecoxib does not affect the normal cells (Gierse et al., 1996). Valdecoxib is a diaryl-substituted isoxazole that exhibits analgesic and antipyretic properties in addition to anti-inflammatory properties in animal models. These COX-2selective diarylheterocyclic inhibitors have been reported to be a reversible competitive inhibitor of COX-1 while demonstrating time-dependent irreversible inhibition of COX-2, which accounts for the potency and selectivity<smiles>Cc1onc(-c2ccccc2)c1-c1ccc(S(N)(=O)=O)cc1</smiles>

demonstrated by members of this structural class (Walkeri et al., 2001). The phenylsulphonamide moiety of the diarylheterocycles associate within a side pocket present in the active site of COX-2, and this pocket is more accessible in COX-2 than in COX-1, which is the result of the substitution of valine for isoleucine at position 523 in COX-1 (Kurumbail et al., 1996).
Received 24 November 2004 Accepted 3 December 2004 Online 11 December 2004 


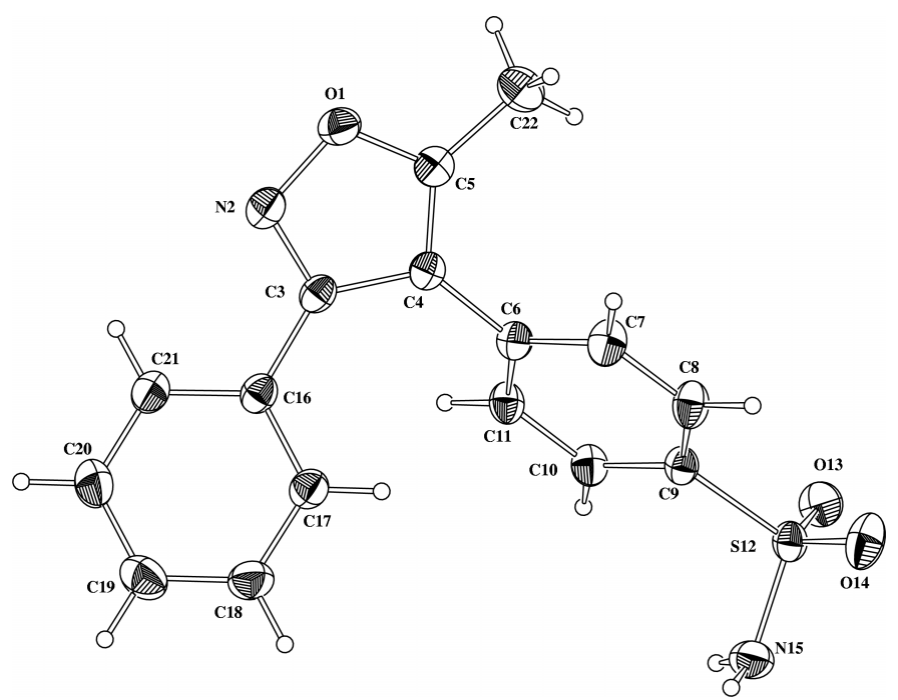

Figure 1

ORTEP-3 (Farrugia, 1997) plot of the title compound, showing $30 \%$ probability displacement ellipsoids and the atom-numbering scheme.

In the title molecule, (I) (Fig. 1), the isoxzaole ring $(A)$ is planar and forms dihedral angles of $54.3(1)$ and $22.2(1)^{\circ}$ with the planes through the $B(\mathrm{C} 6-\mathrm{C} 11)$ and $C(\mathrm{C} 16-\mathrm{C} 21)$ benzene rings, respectively. The $\mathrm{S}$ atom in the sulphonamide group has $s p^{3}$ hybridization. Atom $\mathrm{N} 15$ forms an $\mathrm{N}-\mathrm{H} \cdots \mathrm{O}$ hydrogen bond with atom $\mathrm{O} 13^{\mathrm{i}}$ [symmetry code: (i) $\frac{3}{2}-x, \frac{1}{2}+y, z$, forming chains along the $b$ axis (Fig. 2). An $\mathrm{N}-\mathrm{H} \cdots \pi$ interaction between atom $\mathrm{N} 15$ and ring $C$ of the symmetry-related molecule at $\left(2-x, y-\frac{1}{2}, \frac{1}{2}-z\right)$ occurs, with an $\mathrm{N} \cdots$ centroid (Cg) distance of $3.429(4) \AA$. The isoxazole rings of the inversion-related molecules at $(x, y, z)$ and $(2-x, 1-y$, $1-z$ ) interact via face-to-face $\pi-\pi$ interaction, the $C g \cdots C g$ distance being 3.606 (2) $\AA$ (Fig. 3). In addition to the above interactions, the molecular packing in the crystal structure is further stabilized by a number of weak $\mathrm{C}-\mathrm{H} \cdots \mathrm{O}$ and $\mathrm{C}-$ $\mathrm{H} \cdots \pi$ interactions (Table $1 ; C g 1, C g 2$ and $C g 3$ denote the centroids of rings $A, B$ and $C$, respectively).

\section{Experimental}

Deoxybenzoin $(0.01 M)$ was treated with hydroxylamine hydrochloride $(0.01 M)$ in the presence of sodium acetate to produce the corresponding oxime. When the oxime was deprotonated using $n$ butyllithium ( 2 equivalents) and condensed with ethyl acetate $(25 \mathrm{ml})$ the corresponding isoxazoline was produced. Chlorosulfonic acid $(0.01 \mathrm{M})$ treatment followed by addition of sulfonyl chloride $(0.01 M)$ with aqueous ammonia to the isoxazoline yielded valdecoxib.

\section{Crystal data}

$\mathrm{C}_{16} \mathrm{H}_{14} \mathrm{~N}_{2} \mathrm{O}_{3} \mathrm{~S}$

$M_{r}=314.35$

Orthorhombic, $\mathrm{Pbca}$

$a=12.872(2) \AA$

$b=9.282(3) \AA$

$c=24.761(7) \AA$

$V=2958.4(14) \AA^{3}$

$Z=8$

\author{
$D_{x}=1.412 \mathrm{Mg} \mathrm{m}^{-3}$ \\ Mo $K \alpha$ radiation \\ Cell parameters from 25 reflections \\ $\theta=8-15^{\circ}$ \\ $\mu=0.23 \mathrm{~mm}^{-1}$ \\ $T=293(2) \mathrm{K}$ \\ Rectangular block, colourless \\ $0.35 \times 0.30 \times 0.20 \mathrm{~mm}$
}

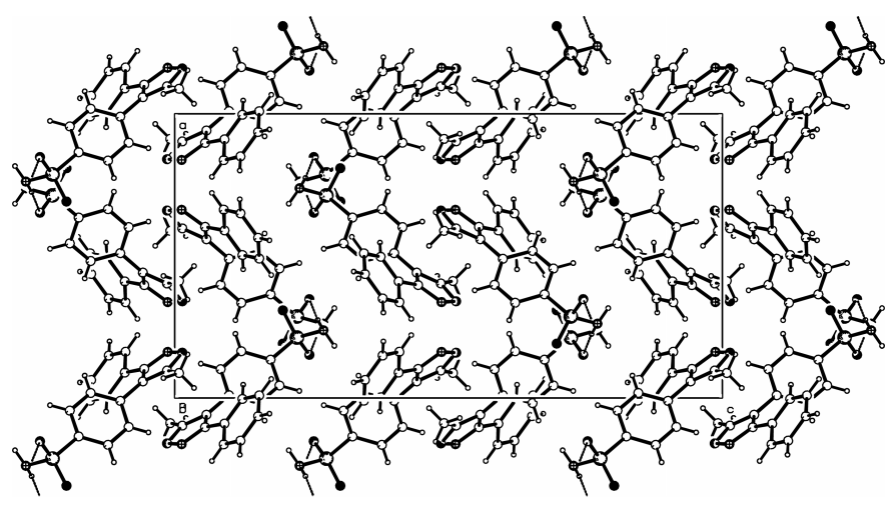

Figure 2

Packing diagram of the molecules, viewed down the $b$ axis. Dotted lines indicate the $\mathrm{N}-\mathrm{H} \cdots \mathrm{O}$ hydrogen bond between atoms $\mathrm{N} 15$ and $\mathrm{O} 13$.

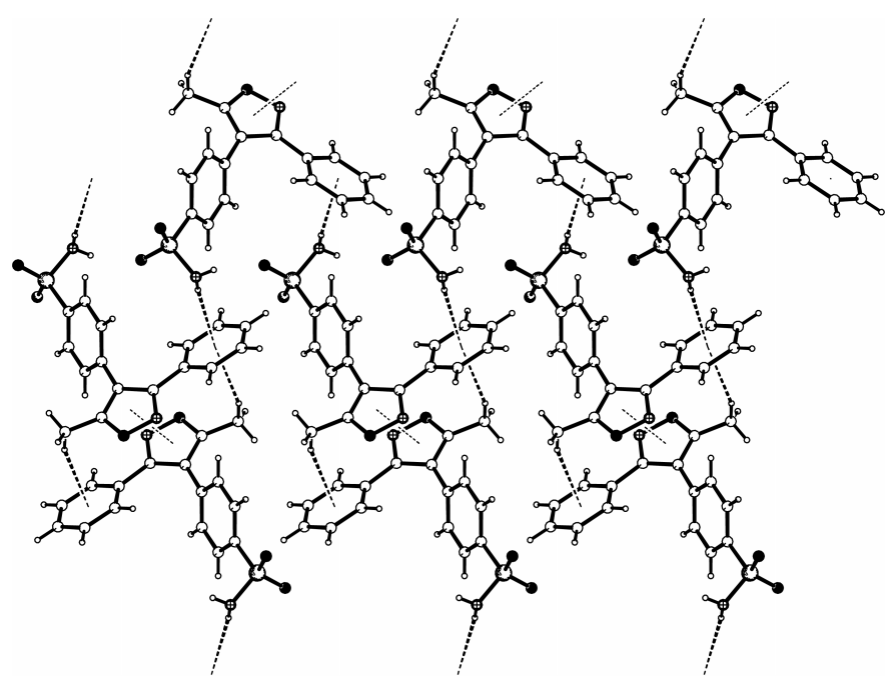

Figure 3

A view, down the $a$ axis, of the $\mathrm{N}-\mathrm{H} \cdots \pi, \mathrm{C}-\mathrm{H} \cdots \pi$ and $\pi \cdots \pi$ interactions (dashed lines).

\section{Data collection}

Enraf-Nonius CAD-4 diffractometer

Non-profiled $\omega / 2 \theta$ scans 4295 measured reflections 4295 independent reflections 2167 reflections with $I>2 \sigma(I)$ $\theta_{\max }=30.0^{\circ}$

\section{Refinement}

Refinement on $F^{2}$

$R\left[F^{2}>2 \sigma\left(F^{2}\right)\right]=0.055$

$w R\left(F^{2}\right)=0.179$

$S=1.03$

4295 reflections

208 parameters

$\mathrm{H}$ atoms treated by a mixture of independent and constrained refinement $h=0 \rightarrow 18$

$k=0 \rightarrow 13$

$l=-34 \rightarrow 0$

3 standard reflections every $120 \mathrm{~min}$ intensity decay: none

$$
\begin{gathered}
w=1 /\left[\sigma^{2}\left(F_{\mathrm{o}}^{2}\right)+(0.0714 P)^{2}\right. \\
\quad+1.6196 P] \\
\text { where } P=\left(F_{\mathrm{o}}^{2}+2 F_{\mathrm{c}}^{2}\right) / 3 \\
(\Delta / \sigma)_{\max }=0.002 \\
\Delta \rho_{\max }=0.32 \mathrm{e}^{-3} \\
\Delta \rho_{\min }=-0.35 \mathrm{e}^{-3}
\end{gathered}
$$


Table 1

Hydrogen-bond geometry $\left(\AA{ }^{\circ}\right)$.

\begin{tabular}{lllll}
\hline$D-\mathrm{H} \cdots A$ & $D-\mathrm{H}$ & $\mathrm{H} \cdots A$ & $D \cdots A$ & $D-\mathrm{H} \cdots A$ \\
\hline $\mathrm{N} 15-\mathrm{H} 15 A \cdots \mathrm{O} 13^{\mathrm{i}}$ & $0.90(1)$ & $2.12(3)$ & $3.010(4)$ & $168(2)$ \\
$\mathrm{N} 15-\mathrm{H} 15 B \cdots C g 3^{\mathrm{ii}}$ & $0.90(1)$ & $2.59(3)$ & $3.429(4)$ & $156(2)$ \\
$\mathrm{C} 7-\mathrm{H} 7 \cdots \mathrm{N} 2^{\text {iii }}$ & 0.93 & 2.82 & $3.429(5)$ & 124 \\
$\mathrm{C} 8-\mathrm{H} 8 \cdots \mathrm{O} 1^{\text {iv }}$ & 0.93 & 2.82 & $3.529(4)$ & 134 \\
$\mathrm{C} 11-\mathrm{H} 11 \cdots \mathrm{O} 13^{\mathrm{v}}$ & 0.93 & 2.65 & $3.383(4)$ & 136 \\
$\mathrm{C} 17-\mathrm{H} 17 \cdots \mathrm{O} 14^{\mathrm{i}}$ & 0.93 & 2.61 & $3.273(4)$ & 128 \\
$\mathrm{C} 18-\mathrm{H} 18 \cdots \mathrm{O} 14^{\mathrm{i}}$ & 0.93 & 2.84 & $3.387(5)$ & 119 \\
$\mathrm{C} 18-\mathrm{H} 18 \cdots \mathrm{O} 13^{\mathrm{vi}}$ & 0.93 & 2.61 & $3.389(5)$ & 142 \\
$\mathrm{C} 19-\mathrm{H} 19 \cdots C g 2^{\text {vi }}$ & 0.93 & 3.10 & $3.708(4)$ & 125 \\
$\mathrm{C} 21-\mathrm{H} 21 \cdots C g 1^{\text {vii }}$ & 0.93 & 2.88 & $3.631(4)$ & 138 \\
$\mathrm{C} 22-\mathrm{H} 22 A \cdots C g 3^{\text {iii }}$ & 0.96 & 2.74 & $3.637(4)$ & 157 \\
\hline
\end{tabular}

Symmetry codes: (i) $\quad-x+\frac{3}{2}, y+\frac{1}{2}, z$; $\quad$ (ii) $\quad-x+2, y-\frac{1}{2},-z+\frac{1}{2}$; $-x+2,-y+1,-z+1$; (iv) $x-\frac{1}{2},-y+\frac{1}{2},-z+1$; (v) $-x+2, y+\frac{1}{2},-z+\frac{1}{2}$; (vi) $x, y+1, z ;$ (vii) $-x+\frac{5}{2}, y+\frac{1}{2}, z . C g 1, C g 2$ and $C g 3$ denote the centroids of rings $A, B$ and $C$, respectively.

Amine $\mathrm{H}$ atoms were located in a difference Fourier map and were refined isotropically, with an $\mathrm{N}-\mathrm{H}$ distance restraint of 0.90 (1) $\AA$. The remaining $\mathrm{H}$ atoms were placed in idealized positions $(\mathrm{C}-$ $\mathrm{H}_{\text {aromatic }}=0.93 \AA$ and $\mathrm{C}-\mathrm{H}_{\text {methyl }}=0.96 \AA$ ) and allowed to ride on their parent atoms, with $U_{\text {iso }}(\mathrm{H})=1.2 U_{\text {eq }}(\mathrm{C})$ or $1.5 U_{\text {eq }}\left(C_{\text {methyl }}\right)$.

Data collection: CAD-4 EXPRESS (Enraf-Nonius, 1994); cell refinement: CAD-4 EXPRESS; data reduction: XCAD4 (Harms \& Wocadlo, 1995); program(s) used to solve structure: SHELXS97
(Sheldrick, 1997); program(s) used to refine structure: SHELXL97 (Sheldrick, 1997); molecular graphics: PLATON (Spek, 2003) and ORTEP-3 (Farrugia, 1997); software used to prepare material for publication: SHELXL97.

SMMS acknowledges the Council of Scientific and Industrial Research for financial support.

\section{References}

Coats, T. L., Borenstein, D. G., Nangia, N. K. \& Brown, M. T. (2004). Clin. Ther. 26, 1249-1260.

Enraf-Nonius (1994). CAD-4 EXPRESS. Enraf-Nonius, Delft, The Netherlands.

Farrugia, L. J. (1997). J. Appl. Cryst. 30, 565.

Gierse, J. K., McDonald, J. J., Hauser, S. D., Rangwala, S. H., Koboldt, C. M. \& Seibert, K. J. (1996). Biol. Chem. 271, 15810-15814.

Harms, K. \& Wocadlo, S. (1995). XCAD4. University of Marburg, Germany. Kurumbail, R. G., Stevens, A. M., Gierse, J. K., McDonald, J. J., Stegeman, R. A., Pak, J. Y., Gildehaus, D., Miyashiro, J. M., Penning, T. D. \& Seibert, K. (1996). Nature (London), 384, 644-648.

Scheen, A. J. \& Malaise, M. (2004). Rev. Med. Liege, 59, 251-254.

Sheldrick, G. M. (1997). SHELXS97 and SHELXL97. University of Göttingen, Germany.

Spek, A. L. (2003). J. Appl. Cryst. 36, 7-13.

Walkeri, M. C., Kurumbail, R. G., Kiefer, J. R., Moreland, K. T., Koboldt, C. M., Isakson, P. C., Seibert, K. \& Gierse, J. K. (2001). Biochem. J. 357, 709718. 